Emrouznejad, A. \& G. Yang (In press) Modelling efficient and anti-efficient frontiers in DEA without explicit inputs, International Journal of Operational Research. Accepted

\title{
Modelling efficient and anti-efficient frontiers in DEA without explicit inputs
}

\author{
Guo-liang Yang ${ }^{\mathrm{a}}$, Ali Emrouznejad ${ }^{\mathrm{b}, 1}$ \\ ${ }^{a}$ Institute of Policy and Management, Chinese Academy of Sciences, Beijing 100190, China \\ b Aston Business School, Aston University, Birmingham, B4 7ET, UK
}

\begin{abstract}
Data envelopment analysis (DEA) is one of the most widely used tools in efficiency analysis of many business and non-profit organisations. Recently, more and more researchers investigated DEA models without explicit input (DEA-WEI). DEA-WEI models can divide DMUs into two categories: efficient DMUs and inefficient DMUs. Usually there is a set of DMUs which are "efficient" so that conventional DEA models could not rank them. In this paper, we first develop a performance index based on efficient and anti-efficient frontiers in DEA-WEI models. Further, the corresponding performance index in DEA-WEI models with quadratic utility terms (quadratic DEA-WEI) is proposed also. Finally, we present two case studies on performance assessment of basketball players and the evaluation of research institutes in Chinese Academy of Sciences (CAS) to show the applicability and usefulness of the performance indices developed in this paper.
\end{abstract}

Keywords. Data envelopment analysis; DEA without explicit input; efficient frontier; anti-efficient frontier

\section{Introduction}

DEA is a mathematical programming method for evaluating efficiency of decision making units (DMUs) with multiple inputs and multiple outputs. It has been widely used in efficiency analysis and performance evaluation of many business and non-profit organisations. More and more research literatures on DEA appear since Charnes et al. (1978) proposed the first CCR model.

\footnotetext{
${ }^{1}$ Corresponding author:

Ali Emrouznejad, Professor and Chair in Business Analytics, Aston Business School, Aston University, Birmingham, UK, a.emrouznejad@aston.ac.uk
} 
Soon after that, Banker et al. (1984) proposed BCC model by considering the assumption of variable returns to scale. Besides these two models, there are also some well-known works, e.g., the additive model (Charnes et al., 1985), the Weight-restricted model (Dyson and Thanassoulis, 1998; Allen et al., 1997). One of the unique features of DEA models is that the assessed DMUs are allowed to assign their most favourable weights to maximise their performance in the evaluation. Cook et al. (2009) and Emrouznejad et al (2008) provided excellent reviews on DEA theories and applications. Most of these DEA models, which were formulated for applications, normally have both inputs and outputs to measure the technical efficiencies of DMUs.

There are many standard application of DEA in the literature (e.g. Khalili-Damghani and Taghavifard 2013, Agarwal et al. 2014 and Pannu et al. 2011). However, more and more researchers identified many applications that there are only input or output variables. In some business and management studies (e.g., Emrouznejad and Amin, 2009; Emrouznejad and Cabanda, 2010), multiple ratio indicators may be used to measure the performance, such as GDP per capita, publication per staff, citation per paper, revenue-expenditure ratio, value-added per employee, profit per cost and so on. In such cases, it is difficult or sometimes impossible to transform the data into the original inputs and outputs. Thus classic DEA models cannot be used to measure the performance of DMUs. Furthermore, in practice there are also many multiple criteria decision problems (MCDM) which need to consider no input variables. Fernandez-Castro and Smith (1994) introduced a seminal model of the General Non-Parametric Corporate Performance (GNCP) that combines all financial ratios to a single measure, using the standard DEA model without any input variables (See also Emrouznejad et al.; 2012). Lovell and Pastor (1999) studied these DEA models systematically and named them as "DEA models without inputs". They have also shown that: " $a$ CCR model without inputs (or without outputs) is meaningless; (ii) a CCR model with a single constant input (or with a single constant output) coincides with the corresponding BCC model." (See also Hollingsworth and Smith, 2003). Simultaneously, Caporaletti et al. (1999) proposed a framework to rate and classify entities described by multiple performance attributes into performers and underperformers. Their approach is equivalent to DEA-WEI models with only outputs. Their model is used by Hai (2007) to assess the performance of nations at the Olympics.

Recently, Yang et al. (2014) proposed generic DEA-WEI models with quadratic utility terms 
after discussing the relationship between multi-attributes utility theory (MAUT) and DEA models without explicit inputs (DEA-WEI), including dual models and some theoretical analysis of DEA-WEI models. Cooper et al. (2009) and Yang et al. (2014) mentioned that DEA-WEI models measure the "effectiveness" of DMUs instead of efficiency because only output variables are considered in the assessment models. Liu et al. (2011) suggested that DEA-WEI could be used to measure efficiency, as well as efficacy, where inputs are not taken into account as seen in assessing examination performances of students, or overall economic power of countries. Due to the consideration that DEA-WEI models are equivalent to the corresponding DEA models with a single constant input, we will still use the concept of efficiency in this paper. Similar to standard DEA, DEA-WEI models can also divide DMUs into two categories: efficient DMUs and inefficient DMUs. It is obvious that usually there are plural DMUs which have the "efficient status" (Anderson and Peterson, 1993; Tone, 2002). Alder et al. (2002) argued that "Often Decision-Makers (DMs) are interested in a complete ranking, beyond the dichotomized classification, in order to refine the evaluation of the units." In the literature supper efficiency models have been used commonly for ranking efficient DMUs (Anderson and Peterson, 1993; Tone, 2002). However there are two shortfalls using supper efficiency for ranking. First there exists infeasibility problem in variable returns to scale radial super-efficiency model (Seiford and Zhu, 1999; Yao, 2005), secondly and more important, Banker and Chang (2006) have recently shown that the super-efficiency procedure is suitable for outlier identification not for ranking efficient units.

Therefore, this paper improves DEA-WEI models using both efficient and anti-efficient frontiers and with the aim of using them for discrimination DEA-WEI results. Further we will extend this approach to the DEA-WEI models with quadratic utility terms (Yang et al. 2014), which suffers the problem that multiple efficient DMUs cannot be discriminated in the case of having quadratic utility terms. In this paper we intend to provide a general framework for classic DEA-WEI models and DEA-WEI models with quadratic utility terms. That is why we select DEA-WEI models to explore this approach instead of general DEA models. This is done by introducing two performance indices based on efficient and anti-efficient frontiers for DEA-WEI models with linear and quadratic utility terms. The earliest work on anti-efficient frontier can be 
traced to "Inverted" DEA model proposed by Yamada et al. (1994). Compared to the standard DEA models which evaluate DMUs from the perspective of optimism, "Inverted" DEA model is to evaluate the performance of DMUs from the perspective of pessimism. Recently, some scholars employed Inverted DEA model to exploit more information from the data in their applications. Paradi et al. (2004) used DEA and Inverted DEA models to identify the worst practices in banking credit analysis. Thanassoulis (1999) used some layering or peeling technique to increase the classification accuracies through the elimination of self-identifiers. Johnson and McGinnis (2008) employed both the efficient and anti-efficient frontiers to identify outliers. Wang and Luo (2006) and $\mathrm{Wu}$ (2006) constructed the best and worst virtual DMUs and simply add them into the existing DMU set to carry out further DEA and Inverted DEA analysis using the extended data set. However, it may not be a wise idea because the PPS will be greatly changed in this case. Amirteimoori (2007) employed the Inverted DEA models to define the anti-efficient frontier. Then he defined a new combined efficiency measures based on the two distances to rank DMUs. However, since the efficiency scores of these DMUs on efficient frontier and anti-efficient frontier are 1 and -1 respectively, this combined efficiency measure is not able to improve discrimination power of DEA models either.

The rest of the paper is structured as follows. Section 2 introduces utility theory and DEA-WEI models, including linear DEA-WEI and quadratic DEA-WEI models, and their dual presentations. The attainable set (AS) and quasi-attainable set (qAS) are defined in Section 3. The efficient frontier of AS and anti-efficient frontier of qAS are also proposed in this section. Alternative performance indices based on efficient and anti-efficient frontiers in DEA-WEI and quadratic DEA-WEI are developed in Section 4. Intersections of the two frontiers have been discussed in Section 5. In Section 6, we will apply the proposed performance indices to the performance assessment of basketball players and an application for measuring performance of research institutions in Chinese Academy of Sciences (CAS). Conclusions and direction for future research appear in Section 7.

\section{Extended utility and DEA-WEI models}

\section{Extended utility function}


Multiple Attribute Utility Theory (MAUT) is designed to handle the trade-offs among multiple objectives. Decisions such as these involve comparing alternatives that have strengths or weaknesses with regard to multiple objectives of interest to DMs. Keeney and Raiffa (1976) and von Winterfeldt and Edwards (1986) presented reviews systematically on MAUT. In MAUT, each DMU receives a score or a utility value for every criterion, and then these scores are aggregated into a multi-attribute utility function to get an overall utility value. As pointed out by Duarte and Reis (2006), two necessary conditions must hold when applying MAUT: (1) The DM is able to set preference relations between pairs of alternatives with respect to every attribute. (2) The DM behaves with pure rationality in the sense that he/she intends to maximize the satisfaction with respect to each single objective.

There is a wide range of applications for MAUT in business and engineering in both public and private sectors. For example, Kainuma and Tawara (2006) proposed a MAUT approach to lean and green supply chain management. Duarte and Reis (2006) developed a projects evaluation system based on MAUT. However, one of the limitations of MAUT is that there is a need on pre-decision information on weights of criteria. Keeny and Raiffa (1976) argued that if $x_{i}$ is "utility independent" of $x_{j}$ for all $j \neq i$, then the following multi-linear utility function is appropriate, given $X=\left(x_{1}, x_{2}, \ldots, x_{n}\right), n \geq 2$ :

$$
\begin{aligned}
u(X)= & \sum_{i=1}^{n} w_{i} u_{i}\left(x_{i}\right)+\sum_{i=1}^{n-1} \sum_{j>i} w_{i j} u_{i}\left(x_{i}\right) u_{j}\left(x_{j}\right)+\sum_{i=1}^{n-2} \sum_{j>i} \sum_{m>j>i} w_{i j m} u_{i}\left(x_{i}\right) u_{j}\left(x_{j}\right) u_{m}\left(x_{m}\right) \\
& +\mathrm{L}+w_{123 \ldots n} u_{1}\left(x_{1}\right) u_{2}\left(x_{2}\right) \mathrm{L} u_{n}\left(x_{n}\right) .
\end{aligned}
$$

where $u_{i}\left(x_{i}\right)$ is a single attribute utility function and is scaled from 0 to 1 . Variable $w_{i}$ is the weight for attribute $i$ where $0 \leq w_{i} \leq 1$, and variables $w_{i j}, w_{i j m}, w_{123 \ldots n}$ denote the impact of the interactions between attributes on preferences respectively. If a more restrictive preference condition called "additive independence" is satisfied, we can reformulate the DMs' preferences as follows:

$$
u\left(x_{1}, \ldots, x_{n}\right)=\sum_{i=1}^{n} w_{i} u_{i}\left(x_{i}\right),
$$


where $0 \leq w_{i} \leq 1$ and $\sum_{i=1}^{n} w_{i}=1$. We let $y_{r j}$ be the value of certain DMU's partial utility function, that is $y_{r j}=u_{r}\left(x_{r j}\right)$. Then MAUT model can be written as follow:

$$
u\left(X_{j}\right)=\sum_{i=1}^{s} w_{i} y_{r j}
$$

where $0 \leq w_{i} \leq 1$ and $\sum_{i=1}^{n} w_{i}=1$

Without loss of generality, we consider that there are $\mathrm{n}$ alternatives or decision making units (DMUs) with s criterions $\left(y_{1}, y_{2}, \ldots, y_{s}\right)$, denoted by $Y_{1}, \ldots Y_{n}$, where every criterion $y_{r} \geq 0$ is desirable. DMs need to assign the weights to each attribute or criterion. Normally, there are subjective and objective approaches to identify weights. For example, the Analytic Hierarchy Process (Saaty 1980, 1986; Forman and Gass, 1999) is one of the subjective approaches and it can decide weights through the eigenvalues and eigenvectors of evaluation matrix of experts' judgements. Among objective approaches, Entropy method (see Hwang and Yoon, 1981; Zeleny, 1982) or Principal Components Analysis can determine the weights only based on the existing data through the entropy or the factor loading (i.e., component loadings) of the data respectively.

All above methods assign the weights by prejudgment. An alternative is to let decision makers (DMs) to choose their weights according the best mix, similar to DEA, where a DM allow each DMU to select the weights of input and output variables to maximise its performance. Therefore we propose the following model:

$$
\begin{gathered}
h^{*}=\max \quad \sum_{r=1}^{s} w_{r} y_{r 0} \\
\text { s.t. }\left\{\begin{array}{c}
\sum_{r=1}^{s} w_{r} y_{r j} \leq 1, j=1, \ldots, n \\
w_{r} \geq 0, \quad r=1, \ldots, s
\end{array}\right.
\end{gathered}
$$

The equivalent form of the above Model (2) appears also in Caporaletti et al. (1999), which developed a framework to rate and classify based on nonparametric frontiers. Toloo (2012) and Toloo (2013) proposed the DEA-WEI with non-Archimedean construct $\varepsilon \in$ 
$\left(0, \max \left\{1 / \sum_{r=1}^{s} y_{r j}: j=1, \ldots, n\right\}\right]$.

The weights for each DMU are assigned by the maximisation formulation in Model (2), which can be viewed to extend utility function method. Model (2) is formulated from optimistic viewpoint for each DMU. Similarly, we can formulate a model from pessimistic viewpoint as follows.

$$
\begin{gathered}
\pi^{*}=\min \quad \sum_{r=1}^{s} w_{r} y_{r 0} \\
\text { s.t. }\left\{\begin{array}{c}
\sum_{r=1}^{s} w_{r} y_{r j} \geq 1, \quad j=1, \ldots, n \\
w_{r} \geq 0, \quad r=1, \ldots, s
\end{array}\right.
\end{gathered}
$$

Yang et al. (2014) argued that linearity cannot reflect evidence enhancement although linear truncation of utility function is the most widely used form in practice. They argued that if in some applications we must emphasize the interactions of two or more indicators, one should use DEA-WEI models with nonlinear terms instead of standard DEA-WEI models. Thus they followed the general form of the utility function and proposed the generic DEA-WEI model as follows.

$$
\begin{gathered}
q h^{*}=\max \quad \sum_{r=1}^{s} w_{r} y_{r 0}+\sum_{r=1}^{s} \sum_{k \geq r}^{s} \omega_{r k} y_{r 0} y_{k 0} \\
\text { s.t. }\left\{\begin{array}{c}
\sum_{r=1}^{s} w_{r} y_{r j}+\sum_{r=1}^{s} \sum_{k \geq r}^{s} \omega_{r k} y_{r j} y_{k j} \leq 1 \\
w_{r} \geq 0, j=1, \ldots, n \\
\omega_{r k} \geq 0, \quad k=r, \ldots, s ; r=1, \ldots, s
\end{array}\right.
\end{gathered}
$$

where $\omega_{r k}$ represents the coefficient of quadratic terms. In Model (4), we can see that quadratic terms appear in the objective function and the first constraint, which can reflect evidence enhancement of two indicators.

Similarly, we have the corresponding quadratic DEA-WEI model from pessimistic viewpoint as follows, which is denoted by quadratic anti-DEA-WEI model in this paper. 


$$
\begin{gathered}
q \pi^{*}=\min \sum_{r=1}^{s} w_{r} y_{r 0}+\sum_{r=1}^{s} \sum_{k \geq r}^{s} \omega_{r k} y_{r 0} y_{k 0} \\
\text { s.t. }\left\{\begin{array}{c}
\sum_{r=1}^{s} w_{r} y_{r j}+\sum_{r=1}^{s} \sum_{k \geq r}^{s} \omega_{r k} y_{r j} y_{k j} \geq 1 \\
w_{r} \geq 0, j=1, \ldots, n \\
\omega_{r k} \geq 0, r=1, \ldots, s, \text { and } k=r, \ldots, s
\end{array}\right.
\end{gathered}
$$

\section{The dual models}

To understand the above utility-like DEA-WEI models more easily and deduce the attainable and quasi-attainable set more directly, we discuss the dual models of Model (2) Model (5) in this section. The dual of Model (2) reads:

$$
\min \left\{\sum_{j=1}^{n} \lambda_{j}^{\prime} \mid \sum_{j=1}^{n} y_{r j} \lambda_{j}^{\prime} \geq y_{r 0}, r=1, \ldots, s ; \lambda_{j}^{\prime} \geq 0, \quad j=1, \ldots, n\right\}
$$

We assume $\theta=1 / \sum_{j=1}^{n} \lambda_{j}^{\prime}$ and $\lambda_{j}=\theta \lambda_{j}^{\prime}$. Thus we know that Model (6) can be transformed into the following Model (7):

$$
\theta_{\text {raidal }}^{*}=\max \left\{\theta \mid \sum_{j=1}^{n} y_{r j} \lambda_{j} \geq \theta y_{r 0}, r=1, \ldots, s ; \sum_{j=1}^{n} \lambda_{j}=1, \lambda_{j} \geq 0, \quad j=1, \ldots, n\right\}
$$

Similarly the dual of Model (3) is presented as follows.

$$
\varphi_{\text {radial }}^{*}=\min \left\{\varphi \mid \sum_{j=1}^{n} \lambda_{j} y_{r j} \leq \varphi y_{r 0}, r=1, \ldots, s ; \sum_{j=1}^{n} \lambda_{j}=1, j=1, \ldots, n\right\}
$$

Model (8) is similar to Model (7) with the aim to minimize the scale factor $\varphi$. Model (4) is the generic quadratic DEA-WEI model proposed by Yang et al. (2014), in which there are quadratic terms in both the objective function and constraints. Here we give the dual model of Model (4). 


$$
\text { s.t. }\left\{\begin{array}{c}
q \theta_{\text {radial }}^{*}=\max \theta \\
\sum_{j=1}^{n} y_{r j} \lambda_{j} \geq \theta y_{r 0}, r=1, \ldots, s \\
\sum_{r=1}^{n} \omega_{r k} y_{r j} y_{k j} \lambda_{j} \geq \theta \omega_{r k} y_{r 0} y_{k 0}, r=1, \ldots, s, k=r, \ldots, s \\
\sum_{j=1}^{n} \lambda_{j}=1, \lambda_{j} \geq 0
\end{array}\right.
$$

It is clear that there are several more constraints in Model (9) than in Model (7). These constraints are constructed by quadratic terms in Model (4). Similar to Model (9), we can easily give the dual model of Model (5) as follows.

$$
\begin{gathered}
q \varphi_{\text {radial }}^{*}=\min \varphi \\
\sum_{j=1}^{n} y_{r j} \lambda_{j} \leq \varphi y_{r 0}, r=1, \ldots, s \\
\sum_{j=1}^{n} y_{r j} y_{k j} \lambda_{j} \leq \varphi \omega_{r k} y_{r 0} y_{k 0}, r=1, \ldots, s, k=r, \ldots, s \\
\omega_{r k}=0 \text { or } 1, r=1, \ldots, s, k=r, \ldots, s \\
\sum_{j=1}^{n} \lambda_{j}=1, \lambda_{j} \geq 0
\end{gathered}
$$

Essentially, Model (9) is a linear mathematical program with constraints including $\sum_{j=1}^{n} \omega_{r k} y_{r j} y_{k j} \lambda_{j} \geq \theta \omega_{r k} y_{r 0} y_{k 0}$, in which quadratic terms $y_{r j} y_{k j}$ appear. Model (10) is the corresponding to Model (9) from pessimistic viewpoint.

\section{Attainable set and quasi-attainable set}

This section focuses on the axiom foundations of the DEA-WEI models. For this purpose, we first define the attainable set and quasi-attainable set for DEA-WEI model. We use these definitions to propose an anti-frontier DEA-WEI model.

Definition 1 (Attainable set): An attainable set $A S$ is a non-empty close subset of $R_{s}^{+}$, which contains all DMUs that are realizable. That is $A S=\left\{f\left(Y_{j}\right) \mid j=1, \ldots, n\right\}$, where 
$f: R_{s}^{+} \rightarrow R_{s}^{+}$. For simplicity, assume $f\left(Y_{j}\right)=Y_{j}$, that is $A S=\left\{Y_{j} \mid j=1, \ldots, n\right\}$.

Definition 2 (Inferior set): The inferior set of $X$ is defined by

$$
I N(X)=\left\{Y \in R_{s}^{+}, Y \leq X\right\}
$$

Assumption 1 (Free-disposal): If an element $X \in A S$, then its inferior set belongs to it, i.e. for any $Y \in I N(X)$, then $Y \in A S$.

If the Assumption (1) holds, then the AS set can be extended as follows:

$$
A S=\bigcup_{j=1}^{n} I N\left(Y_{j}\right) \text { or } A S=\left\{Y \mid Y \leq \sum_{j=1}^{n} \lambda_{j} Y_{j}, \sum_{j=1}^{n} \lambda_{j}=1, \lambda_{j}=0 \text { or } 1\right\}
$$

Definition 3 (Efficient frontier of AS): For an element $Y \in A S$, if there does not exist $X \in A S$, which satisfies $Y<X$, then $Y$ is on the efficient frontier of AS.

Assumption 2 (Convexity): If $X, Y \in A S$, then $\lambda X+(1-\lambda) Y \in A S$, for any $0 \leq \lambda \leq 1$

If the assumptions (1) and (2) hold, the attainable set can be further extended as follows:

$$
A S=\left\{Y \mid Y \leq \sum_{j=1}^{n} \lambda_{j} Y_{j}, \sum_{j=1}^{n} \lambda_{j}=1, \lambda_{j} \geq 0\right\}
$$

As discussed earlier, Model (7) measures the relative distance between the $\mathrm{DMU}_{0}$ and the frontier of Attainable set.

Similarly, we can define quasi-attainable set as follows.

$$
q A S=\left\{Y \mid Y \geq \sum_{j=1}^{n} \lambda_{j} Y_{j}, \sum_{j=1}^{n} \lambda_{j}=1, \lambda_{j} \geq 0\right\}
$$

Note, AS and qAS are all closed and convex sets.

Based on the definition of quasi-attainable set, we can define the anti-frontier of qAS as follows.

Definition 4 (Anti-efficient frontier of qAS): For an element $Y \in q A S$, if there does not exist $X \in q A S$, which satisfies $X<Y$, then $Y$ is on the anti-frontier of $q A S$.

Figure 1 shows the efficient and anti-efficient frontier in the case of two indicators (outputs). We can also measure the relative distance between the $\mathrm{DMU}_{0}$ and the anti-frontier of 
quasi-attainable set.

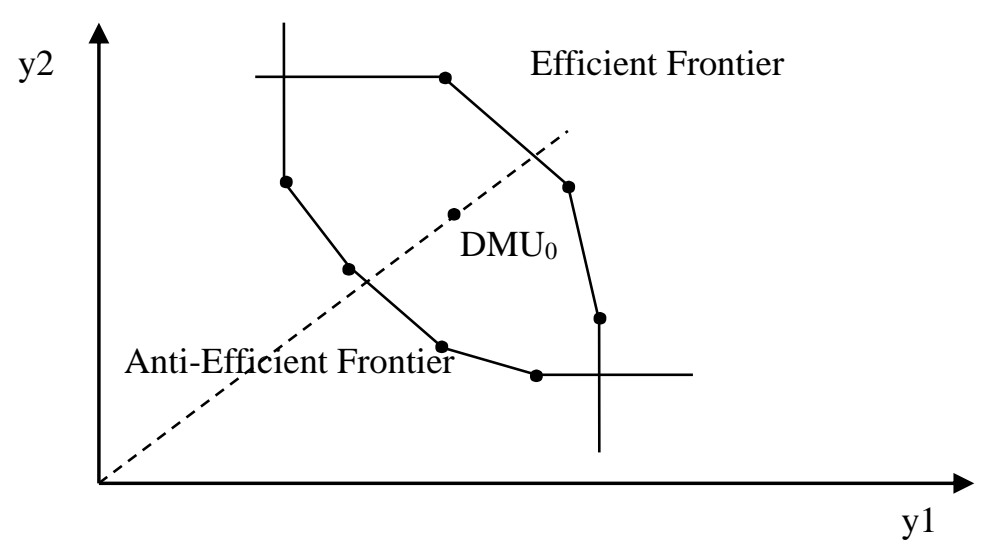

Figure 1. Efficient and anti-efficient frontiers

Similar to Yang et al. (2014) who showed that the optimal objective value of Model (2) is the reciprocal of that of Model (7), i.e., $h^{*}=1 / \theta^{*}$, we can proof the following theorems easily.

Theorem 1: The optimal objective value of Model (3) is equal to the reciprocal of that of Model (8), i.e., $\pi^{*}=1 / \phi^{*}$.

Proof: The dual model of (3) is:

$$
\max \left\{\sum_{j=1}^{n} \lambda_{j} \mid \sum_{j=1}^{n} y_{r j} \lambda_{j} \leq y_{r 0}, r=1, \ldots, s ; \lambda_{j} \geq 0, \quad j=1, \ldots, n\right\}
$$

By the constraints of Model (11), we could find $\sum_{j=1}^{n} \lambda_{j}>0$. We let $t=\sum_{j=1}^{n} \lambda_{j}$ and $\lambda_{j}^{\prime}=\lambda_{j} / t$, then Model (11) can be transformed to the following model (12):

$$
\max \left\{t \mid \sum_{j=1}^{n} \lambda_{j}^{\prime} y_{r j} \leq(1 / t) y_{r 0}, r=1, \ldots, s ; \sum_{j=1}^{n} \lambda_{j}^{\prime}=1, \lambda_{j}^{\prime} \geq 0, j=1, \ldots, n\right\}
$$

Assume $\theta=1 / t$ and substitute the $\lambda_{j}$ for $\lambda_{j}^{\prime}$, then we can easily conclude that the optimal objective value of Model (12) is the reciprocal of that of Model (3). Q.E.D.

Theorem 2: The optimal objective value of Model (4) is the reciprocal of that of Model (9), that is $q h^{*}=1 / q \theta^{*}$. The proof is similar to Theorem 1 , and omitted. Q.E.D.

Theorem 3: The optimal objective value of Model (5) is equal to the reciprocal of that of 
Model (10), i.e., $q \pi^{*}=1 / q \phi^{*}$. The proof is similar to Theorem 1 , and omitted. Q.E.D.

\section{Intersections of Efficient and Anti-Efficient Frontiers}

As seen in Figure 1, it is evident that the efficient and anti-efficient frontiers can meet sometimes, i.e. there exist DMUs that are both good and bad references for the evaluation. In fact this is a major limitation for the proposed approach that we address in this section. We first discuss a sufficient condition to ensure that the efficient and anti-efficient frontiers will not intersect so that it is guarantee that our method works without any issue. We then further discuss how the cases where the two frontiers do meet.

Using Model (2) and Model (3), we can identify the $s_{1}$ efficient DMUs, denoted by $Y_{1}^{e}$, $Y_{2}^{e}, \ldots, Y_{s_{1}}^{e}$, and the $s_{2}$ anti-efficient DMUs, denoted by $Y_{1}^{a}, Y_{2}^{a}, \ldots, Y_{s_{1}}^{a}$. We let $\Phi$ and $\Theta$ represent the convex combinations of the $s_{1}$ efficient DMUs and the $s_{2}$ anti-efficient DMUs respectively, i.e. (a) Set $\Phi$ is defined as the convex combinations of $\lambda_{1} Y_{1}^{e}+\lambda_{2} Y_{2}^{e}+\ldots+\lambda_{s_{1}} Y_{s_{1}}^{e}$ where $\lambda_{1}+\lambda_{2}+\ldots+\lambda_{s_{1}}=1$ and $\lambda_{1}, \lambda_{2}, \ldots, \lambda_{s_{1}} \geq 0 ;$ (b) Set $\Theta$ is defined as $\lambda_{1}^{\prime} Y_{1}^{a}+\lambda_{2}^{\prime} Y_{2}^{a}+\ldots+\lambda_{s_{2}}^{\prime} Y_{s_{2}}^{a}$ where $\lambda_{1}^{\prime}+\lambda_{2}^{\prime}+\ldots+\lambda_{s_{2}}^{\prime}=1$ and $\lambda_{1}^{\prime}, \lambda_{2}^{\prime}, \ldots, \lambda_{s_{2}}^{\prime} \geq 0$

Assume $E F_{e}$ and $E F_{a}$ denote the efficient and anti-efficient frontiers, respectively. Thus we have $E F_{e} \subset \Phi$ and $E F_{a} \subset \Theta$. It is clear that if there are no intersections between $\Phi$ and $\Theta$, then $E F_{e}$ and $E F_{a}$ must not intersect. Therefore we can have the following sufficient condition that can ensure there are no intersections between $\Phi$ and $\Theta$. We consider the following system of linear inequalities:

$$
\left\{\begin{array}{c}
\lambda_{1} Y_{1}^{e}+\lambda_{2} Y_{2}^{e}+\ldots+\lambda_{s_{1}} Y_{s_{1}}^{e}-\lambda_{1}^{\prime} Y_{1}^{a}-\lambda_{2}^{\prime} Y_{2}^{a}-\ldots-\lambda_{s_{2}}^{\prime} Y_{s_{2}}^{a}=0 \\
\lambda_{1}+\lambda_{2}+\ldots+\lambda_{s_{1}}=1 \\
\lambda_{1}^{\prime}+\lambda_{2}^{\prime}+\ldots+\lambda_{s_{2}}^{\prime}=1 \\
\lambda_{1}, \lambda_{2}, \ldots, \lambda_{s_{1}} \geq 0 ; \lambda_{1}^{\prime}, \lambda_{2}^{\prime}, \ldots, \lambda_{s_{2}}^{\prime} \geq 0
\end{array}\right.
$$

where $\lambda_{1}, \ldots, \lambda_{s_{1}}, \lambda_{1}^{\prime}, \ldots, \lambda_{s_{2}}^{\prime}$ are unknown coefficients. 
If there is no feasible solution in (13), we can ensure that the efficient and anti-efficient frontiers will not intersect. It is clear that we can introduce the following auxiliary linear programming with slacks variables to determine whether or not there is feasible solution in (13) (see, e.g. Dantzig (1998) for more details).

$$
\begin{aligned}
& \min \mathbf{g}={ }_{i=1}^{s+2} v_{i}
\end{aligned}
$$

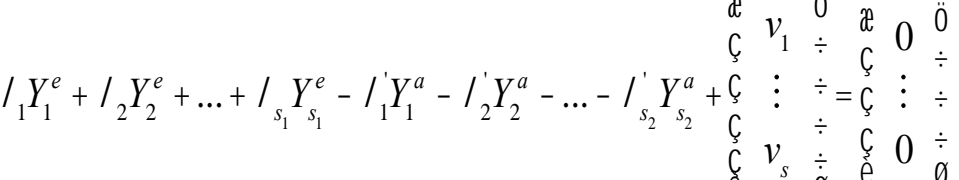

s.t.

$$
\begin{aligned}
& { }_{1}+{ }_{2}+\ldots+{ }_{s_{1}}+v_{s+1}=1 \\
& { }_{1}^{1}+{ }_{2}+\ldots+{ }_{s_{2}}+v_{s+2}=1 \\
& 1,{ }_{2}, \ldots,{ }_{s_{1}} 0 ;_{1},{ }_{2}, \ldots,{ }_{s_{2}} 0 ; v_{1}, \ldots, v_{s+2}
\end{aligned}
$$

where $\lambda_{1}, \ldots, \lambda_{s_{1}}, \lambda_{1}^{\prime}, \ldots, \lambda_{s_{2}}^{\prime}$ are original unknowns and $v_{1}, \ldots, v_{m+s+2}$ are slacks.

It is clear that Model (14) has feasible solution, e.g. $\lambda_{1}, \ldots, \lambda_{s_{1}}=0 ; \lambda_{1}^{\prime}, \ldots, \lambda_{s_{2}}^{\prime}=0$; $v_{1}, \ldots, v_{s}=0 ; v_{s+1}=1 ; v_{s+2}=1$. Hence we have the following theorem:

Theorem 4: There exists no intersection between $\Phi$ and $\Theta$, if and only if the optimal value of objective function in Model (14) is positive.

Proof: If the optimal value is zero, then there is a feasible solution such that $v_{1}=0, \ldots, v_{m+s+2}=0$. Thus $\Phi$ and $\Theta$ has at least one intersection. If the minimal value is larger than zero, suppose that $\Phi$ and $\Theta$ have one intersection so that there exist feasible $\lambda_{1}, \ldots, \lambda_{s_{1}}, \lambda_{1}^{\prime}, \ldots, \lambda_{s_{2}}^{\prime}$ such that $v_{1}=0, \ldots, v_{m+s+2}=0$. Then, it is clear that this is a feasible solution of Model (14) and thus the minimal value should be zero, which is a contradiction.

\section{Q.E.D.}

Thus if the optimal value of objective function in Model (14) is positive, there exists no feasible solution in (13). Therefore, we have a sufficient condition to ensure there is no intersection between efficient and anti-efficient frontiers. 
However in real applications, often there exist DMUs on both the efficient and anti-efficient frontiers. The possible explanation for being on the anti-efficient frontier is that it may have gone exceedingly to achieve its superiority in some areas, and this has brought some side effects. Thus logically we should not consider it as a bad reference. One possibility is to consider it as an outlier in the evaluation and treat it differently. However often we have to evaluate it together. Therefore we should remove it from the construction of the anti-efficient frontier, although it is still included on the efficient frontier. Following this analysis, whenever there exist DMUs on both efficient and anti-efficient frontiers, we will remove them from the anti-efficient DEA-WEI Model (3), and apply Theorem (4) to make sure that the two frontiers do not intersect. For these DMUs we will use the super-anti-efficiency model to compute their anti-efficiencies. Thus we have the following procedure for full ranking of DMUs:

Step 1: Remove the DMUs on both the efficient and anti-efficient frontiers from Model (3).

Step 2: Apply the Theorem (4) to make sure that the efficient frontier and the new anti-efficient frontiers do not intersect.

Step 3: Compute the super-anti-efficiencies of the removed DMUs using the following super-anti-efficiency Model (15) and Model (16):

$$
\begin{gathered}
\varphi_{\text {super }}^{*}=\min \varphi \\
\text { s.t. }\left\{\begin{array}{l}
\sum_{j=1, j \neq j_{0}}^{n} y_{r j} \lambda_{j} \leq \varphi y_{r 0}, r=1, \ldots, s \\
\sum_{j=1, j \neq j_{0}}^{n} \lambda_{j}=1, \lambda_{j} \geq 0, j=1, \ldots, n
\end{array}\right. \\
q \varphi_{\text {sup } r}^{*}=\min \varphi \\
\text { s.t. }\left\{\begin{array}{c}
\sum_{j=1, j \neq j_{0}}^{n} y_{r j} \lambda_{j} \leq \varphi y_{r 0}, r=1, \ldots, s \\
\sum_{j=1, j \neq j_{0}}^{n} y_{r j} y_{k j} \lambda_{j} \leq \varphi y_{r 0} y_{k 0}, r=1, \ldots, s, k=r, \ldots, s \\
\sum_{j=1, j \neq j_{0}}^{n} \lambda_{j}=1, \lambda_{j} \geq 0, j=1, \ldots, n
\end{array}\right.
\end{gathered}
$$

Model (16) is the corresponding super-anti-efficiency model of Model (10).

Step 4: Compute the performance indicators proposed in Section 5 and rank these DMUs. 
In Section 3, in order to show the axiom foundations of the DEA-WEI models, we defined attainable set and quasi-attainable set and efficient and anti-efficient frontiers. Based on these definitions, we will propose intuitively two alternative performance indices based on efficient and anti-efficient frontiers in classic DEA-WEI model and DEA-WEI model with quadratic terms respectively in the following section.

\section{Alternative performance indices based on efficient and anti-efficient frontiers}

In this section, we will introduce alternative performance indices based on efficient and anti-efficient frontiers. Specifically, we use Model (7) (10) to develop two new performance indices using DEA-WEI and quadratic DEA-WEI models.

It is easy to see that Model (7) Model (10) are DEA-WEI models with radial measurement. Specially, in Model (9) and Model (10), quadratic terms appear in constraints. It should be noted that if $a_{r k}=0$, the corresponding quadratic terms will disappear in both Model (9) and Model (10).

Based on Model (7) and Model (8), we propose a new performance index (Index 1) shown in formula (17) using DEA-WEI model.

$$
e_{0}^{*}=1 / \theta_{\text {radial }}^{*}+\varepsilon *\left(1-\varphi_{\text {radial }}^{*}\right)^{2}
$$

where $\varepsilon>0$ is a non-Archimedean infinitesimal. That is, $\varepsilon>0$ is smaller than any positive real number. The new performance measure in formula (17) means DMUs will be ranked using the first and second terms in lexicographical order. For example, if we wish to evaluate $\mathrm{DMU}_{1}$ and $\mathrm{DMU}_{2}$, we first use $1 / \theta_{\text {radial }}^{*}$ to compare their performance. If $1 / \theta_{\text {radial }}^{*}\left(D M U_{1}\right)>($ or $<)$ $1 / \theta_{\text {radial }}^{*}\left(D M U_{2}\right)$ then $\mathrm{DMU}_{1}$ is considered to perform better (or worse) than $\mathrm{DMU}_{2}$. If $1 / \theta_{\text {radial }}^{*}\left(D M U_{1}\right)=1 / \theta_{\text {radial }}^{*}\left(D M U_{2}\right)$, then we use $\left(1-\varphi_{\text {radial }}^{*}\right)$ to compare the performance of $\mathrm{DMU}_{1}$ and $\mathrm{DMU}_{2}$. Note that this index is almost the same as the quadratic DEA-WEI score

\footnotetext{
${ }^{2}$ When $\mathrm{DMU}_{0}$ is an intersection between efficient and anti-efficient frontiers, we should substitute $\varphi_{\text {super }}^{*}$ in Model (17) for $\varphi_{\text {radial }}^{*}$.
} 
except for those efficient DMUs.

Similarly, we define the following index (Index 2) for quadratic DEA-WEI model based on Model (9) and Model (10) as

$$
q e_{0}^{*}=1 / q \theta_{\text {radial }}^{*}+\varepsilon *\left(1-q \varphi_{\text {radial }}^{*}\right)^{3}
$$

Using these two indices, we have full rankings of DMUs according to the numerical value of $e_{0}^{*}$ or $q e_{0}^{*}$, which depends on the utility function of DMs. If the DMs' preference structure satisfies the condition of "additive independence", we could select Index $1\left(e_{0}^{*}\right)$ to rank DMUs, the higher value of index 1 means that the DMU is closer to good frontier. Otherwise, we should choose Index $2\left(q e_{0}^{*}\right)$ to rank DMUs, the higher value of index 2 means that the DMU is farther to bad frontier.

\section{Illustrative examples}

In this section, we illustrate two applications to show the practicality of the proposed approach: The first application on performance analysis of basketball player and basketball centres explains the use of Index 1 (in formula 17); while the second application on evaluation of Chinese Academy of Sciences (CAS) institutions explains the use of Index 2 (in formula 18) and its use to discriminate the performance to produce full rankings for CAS institutes.

\subsection{An application for ranking basketball players/ centres}

Cooper et al. (2009) assessed the performance of Spanish basketball players in Spanish Premier Basketball League (called ACB). They used the data taken from http://www.acb.com/ and corresponded to the $2003-2004$ season. In this application sample of 172 players consisting of those who have played at least 17 games (half a regular season). Similar to Cooper et al. (2009) we consider only those who had played a large enough number of games to reflect their performances reliably. These 172 players had been classified into the five following groups according to their position: playmaker, guard, small forward, power forward and centre. The idea

\footnotetext{
${ }^{3}$ When $\mathrm{DMU}_{0}$ is an intersection between efficient and anti-efficient frontiers, we should substitute $q \varphi_{\text {super }}^{*}$ in Model (18) for $q \varphi_{\text {radial }}^{*}$.
} 
is to have homogenous samples when assessing the efficiency of the players.

The following indicators have been selected as evaluation indicators for the main aspects of the game: shooting, rebounding, ball handling and defense. In particular, the proposed summary of indicators to be included in the model has made possible an important reduction of the dimensionality of the output space compared to the large number of factors used by the ACB (Spanish Premier Basketball League) index. We also use the same variables as in Cooper et al. (2009) for measuring the performances of playmakers and centres as representative cases. Here is list of variables:

(1) Adjusted field goal $(\mathrm{AFG})=(\mathrm{PTS}-\mathrm{FTM}) \times \mathrm{AFG} \%$, where $\mathrm{PTS}=$ points made $($ per game $)$, $\mathrm{FTM}=$ free throws made (per game) and $\mathrm{AFG} \%$, called "adjusted field goal percentage", is defined as $(\mathrm{PTS}-\mathrm{FTM}) /(2 \times \mathrm{FGA})$, where FGA is the number of field goal attempts. AFG\% is used in NBA statistics (see http://sports.espn.go.com/nba/statistics/) for the purpose of measuring "shooting" efficiency by taking into account the total points a player produces through his field goal attempts. The intuition behind this adjustment is largely to evaluate the impact of "three-point shooting". Therefore, AFG is a shooting indicator adjusted for opportunities. We could have separately considered PTS-FTM and AFG\% but we preferred to aggregate both variables into AFG in order to avoid mixing a percentage with a volume measure.

(2) Adjusted free throw $(\mathrm{AFT})=\mathrm{FTM} \times \mathrm{FT} \%$, where FT\% is the free throw successes percentage. Our comments on the mix of percentages with volume measures are also applicable to this variable.

(3) Rebounds (REB): the number of rebounds per game.

(4) Assists (AST): the number of assists per game.

(5) Steals (STE): the number of steals per game.

(6) Inverse of turnovers (ITURN). We have used the inverse of the number of turnovers per game in order to treat the information regarding this indicator as an output that decreases with increases in turnovers, instead of an input. This approach is used because it enables 
us to obtain an index with the same form as the one used by the ACB league.

(7) Non-made fouls own $(\mathrm{NFO})=5$-FO, FO being the number of fouls made (per game) by the assessed player. The purpose of this transformation is the same as in the previous variable, ITURN.

(8) Fouls opposite (FOPP): the number of fouls per game the opposite players have made on the player that is being assessed.

The data for these indicators have been reproduced in Table A-1 and A-2, respectively, for 41 playmakers and 44 centres.

\subsubsection{Assessment of playmakers}

We can see from Table 1 in Cooper et al. (2009) that the performance indexes of four playmakers (Bennett, Bullock, Prigioni and Sánchez) are all equal to 1. That is to say that they are all fully efficient. As Alder et al. (2002) argued that DMs are interested in a complete ranking in order to refine the evaluation of units. To address this issue, we refer to the information provided by the anti-efficient frontier. We use the steps in Section 4 and performance Index 1 (see formula 17) in Section 5, hence we obtained the full ranking of these playmakers which are shown in Column 14 of Table A-1. Compared with the results in Cooper et al. (2009), we know that the performances of 4 fully effective playmakers are discriminated in order of: Prigioni $>$ Bennett $>$ Bullock > Sánchez.

\subsubsection{Assessment of centres}

Table 4 in Cooper et al. (2009) shows that the performance indexes of four centres (David, Garcés, Kambala, Scott and Thompson) are equal to 1 . In other words, they are the fully efficient centres with best performance. In a similar way, and to discriminate the performances of these four fully efficient centres, we refer to the information provided by the anti-efficient frontier. We use the steps in Section 4 and performance Index 1 (see formula 7) in Section 5, hence the full ranking of these centres are shown in Column 14 of Table A-2. Compared with the results in

Cooper et al. (2009), we can see that the performances of 5 fully effective centres are discriminated as Thompson $>$ David $>$ Garcés $>$ Scott $>$ Kambala .

\subsection{Evaluation of research institutes in Chinese Academy of Sciences (CAS)}


In 2005, CAS began to attempt the Comprehensive Quality Evaluation (CQE) system for the evaluation of its affiliated institutes. The CQE is an effective combination of quantitative and qualitative evaluation, peer-review results and management experts' comments. There are several steps in CQE system, such as self-evaluation of institutes, evaluation of institutes' strategic planning, peer reviews for research quality, previous evaluation results, on-site review, etc. Yang et al. (2014) proposed an example on evaluation of research institutes using DEA-WEI in CAS. In this evaluation, the DMs in CAS have chosen to add a quadratic term in the utility function to reflect its emphasis on training and external grant because the importance of training graduates and obtaining external funding was emphasized by CAS for the sustainable development of its institutes. Consequently, In this case, there will be a quadratic terms as shown in Model (9) and Model (10). Thus we can use Index 2 to discriminate their performances.

In this paper, we carry out a pilot study on applying the new performance index (Index 2) to evaluate the efficiency of 16 research institutes in Chinese Academy of Sciences (CAS). They are comparable in the sense that they conduct researches in the similar fields and have identities in research activities.

Within the framework of the CQE, CAS headquarter uses several quantitative indicators to monitor multiple-inputs and multiple-outputs of research institutes each year. The data of the indicators used in this paper come from the quantitative monitoring report in 2010 in CAS and Statistical Yearbook of CAS in 2010.

However, the decision makers (DMs) in CAS prefer to use ratio data to evaluate those institutes based on the consideration of outputs per capita in the affiliated institutes (see Yang et al. 2014). Thus, selected by the DMs, we use DEA-WEI and anti DEA-WEI with five variables as follows:

$$
\begin{gathered}
y_{1 j}=\text { SCI Pub. / Staff; } \quad y_{2 j}=\text { High Pub. / Staff; } \quad y_{3 j}=\text { Grad. Enroll. / staff; } \\
y_{4 j}=\text { Exter. Fund. / staff; } y_{5 j}=\text { Awards / Staff. }
\end{gathered}
$$

Therefore, in this paper, we use the following ratio indicators to measure the performance of these institutes.

\footnotetext{
----- [Table 1 about here] ------
} 
Before running these models we standardize the output variables by dividing each variable to the maximum value of that variable, i.e. $y_{r j}=y_{r j} / \max _{j} y_{r j}, r=1 \ldots 5$, and the results are shown in Table 2 as follows:

\section{----- [Table 2 about here] -----.-}

Because these institutes mainly conduct basic research, SCI Publications and High-quality publications are very important. Also external funding is the focus for sustainable development for institutes in CAS. So, CAS encourages researchers to gain more funds and produce more SCI papers. Thus we consider the quadratic terms could be $y_{1 j} * y_{4 j}$. Hence, we will use the new performance index (Index 2 in formula 18) to evaluate these institutes. We first run Model (9) to have the performance scores of DMUs and their rankings listed in the second and the third columns of Table 4, respectively. Second, we employ Model (10) to obtain the information from anti-efficient frontier, hence the anti-scores are listed in the fourth column in Table 4. According to the performance Index 2 (see formula 18), we can have full rankings of 16 research CAS institutes as shown in Table 3 (See Column 6).

\section{----- [Table 3 about here] -------}

From Table 3, we can see that $\mathrm{DMU}_{1}, \mathrm{DMU}_{2}, \mathrm{DMU}_{3}, \mathrm{DMU}_{6} \mathrm{DMU}_{10}$, and $\mathrm{DMU}_{12}$ are all efficient DMUs in Model (9). That is to say that Model (9) cannot discriminate the performance of these six DMUs. Thus we use the information from the anti-efficient frontier. The anti-efficient scores of these 16 institutes are listed in Column 4 in Table 3. We can test the intersections of efficient and anti-efficient frontiers using Theorem (4). We find that the there is no intersection between efficient and anti-efficient frontiers. Using Index 2 based on efficient and anti-efficient frontiers produced from Model (9) and Model (10) respectively, we can have full ranking of these 16 basic research institutes as shown in Column 6. In particular, we can see that $\mathrm{DMU}_{6}>\mathrm{DMU}_{10}>$ $\mathrm{DMU}_{2}>\mathrm{DMU}_{3}>\mathrm{DMU}_{12}>\mathrm{DMU}_{1}$

\section{Conclusions}

DEA-WEI models can classify DMUs into two categories: efficient DMUs and inefficient DMUs. As Anderson and Peterson (1993) and Tone (2002) mentioned, usually there are plural 
DMUs which have the "efficient status". Alder et al. (2002) argued that in order to refine the evaluation of the units, DMs are interested in a complete ranking. To address this issue, in this paper we first developed a performance index based on efficient and the anti-efficient frontiers in DEA models without explicit inputs (DEA-WEI). Furthermore, we proposed the corresponding performance index in DEA-WEI models with quadratic utility terms (quadratic DEA-WEI). The results of illustrative examples showed the features of these two new performance indices. We find that these two indices can discriminate DMUs with "efficient status" in DEA-WEI models and quadratic DEA-WEI models respectively.

\section{Acknowledgements}

The first author would like to acknowledge the support of the National Natural Science Foundation of China (Nos. 71201158, 71671181).

\section{References}

[1] Adler N, Friedman L, Sinuany-Stern Z (2002). Review of ranking methods in the data envelopment analysis context. European Journal of Operational Research 140, 249-265.

[2] Agarwal, S., Yadav, S.P., Singh, S.P. (2014). Sensitivity analysis in data envelopment analysis. International Journal of Operational Research 19(2), 174-185.

[3] Allen R, Athanassopoulos A, Dyson RG, Thanassoulis E (1997). Weights restrictions and value judgments in data envelopment analysis: Evolution, development and future directions. Annals of Operations Research 73, 13-34.

[4] Amirteimoori A (2007). DEA efficiency analysis: Efficient and anti-efficient frontier. Applied Mathematics and Computation 186, 10-16.

[5] Andersen P, Petersen NC (1993). A procedure for ranking efficient units in DEA. Management Science 39, 1261-1264.

[6] Banker RD, Charnes A, Cooper WW (1984). Some models for estimating technical and scale inefficiencies in data envelopment analysis. Management Science 30, 1078-1092.

[7] Caporaletti, L.E., Dula, J.H., \& Womer, N.K. (1999). Performance evaluation based on multiple attributes with nonparametric frontiers. Omega-The International Journal of Management Science 27, 637-645.

[8] Charnes A, Cooper WW, Li SL (1989). Using DEA to evaluate Relative efficiencies in the Economic Performance of Chinese Cities. Socio-economic Planning Science 23, 325-344.

[9] Charnes A, Cooper WW, Golany B, Seiford L, Stutz J (1985). Foundations of data envelopment analysis for Pareto-Koopmans efficient empirical production functions. Journal 
of Econometrics 30, 91-107.

[10] Charnes A, Cooper WW, Rhodes EL (1978). Measuring the efficiency of decision making units. European Journal of Operational Research 2, 429-444.

[11] Cook WD, Seiford LM (2009). Data envelopment analysis (DEA)-Thirty years on. European Journal of Operational Research 192, 1-17.

[12] Cooper WW, Ruiz JL, Sirvent I (2009). Selecting non-zero weights to evaluate effectiveness of basketball players with DEA. European Journal of Operational Research 159, 563-574.

[13] Dantzig, GB (1998) Linear Programming and Extensions. Princeton University Press, New York.

[14] Dyson RG, Thanassoulis E (1988). Reducing weight flexibility in Data Envelopment Analysis. Journal of the Operational Research Society 39,563-576.

[15] Duarte BPM, Reis A (2006). Developing a projects evaluation system based on multiple attribute value theory. Computers \& Operations Research 33(5), 1488-1504.

[16] Emrouznejad A, Amin GR (2009). DEA models for ratio data: Convexity consideration. Applied Mathematical Modelling 33, 486-498.

[17] Emrouznejad A, Cabanda E (2010). An aggregate measure of financial ratios using a multiplicative DEA model. International Journal of Financial Services Management 4(2), 114-126.

[18] Emrouznejad, A., B. R. Parker and G. Tavares (2008). "Evaluation of research in efficiency and productivity: A survey and analysis of the first 30 years of scholarly literature in DEA." Socio-Economic Planning Sciences 42(3): 151-157

[19] Emrouznejad, A., Rostamy-Malkhalifeh, M., Hatami-Marbini, A. and Tavana, M. (2012). "General and Multiplicative Non-Parametric Corporate Performance Models with Interval Ratio Data." Applied Mathematical Modelling, 36 (11): 5506-5514

[20] Forman EH, Gass SI (1999). The Analytic Hierarchy Process-An Exposition. Operations Research 49, 469-486.

[21] Hai, H.L. (2007). Using vote-ranking and cross-evaluation methods to assess the performance of nations at the Olympics. WSEAS Transactions on Systems 6(6), 1196-1205.

[22] Hollingsworth, B. P.C. Smith, The use of ratios in data envelopment analysis, Applied Economics Letters 10 (2003) 733-735.

[23] Hwang CL, Yoon K (1981). Multiple Attribute Decision Making: Methods and Applications. Springer-Verlag, Berlin.

[24] Johnson AL, McGinnis LF (2008). Outlier detection in two-stage semiparametric DEA models. European Journal of Operational Research 187, 629-635.

[25] Keeney RL, Raiffa H (1976). Decisions with Multiple Objectives. Wiley, New York.

[26] Khalili-Damghani, K.; Taghavifard, B. (2013). Sensitivity and stability analysis in two-stage DEA models with fuzzy data. International Journal of Operational Research 17(1), 1-37. 
[27] Liu WB, Zhang DQ, Meng W, Li XX, Xu F (2011). A study of DEA models without explicit inputs. Omega, The International Journal of Management Science 39, 472-480.

[28] Lovell CAK, Pastor JT (1999). Radial DEA models without inputs or without outputs. European Journal of Operational Research 188, 46-51.

[29] Lozano S, Gutierrez E , Moreno, P (2015). Network DEA approach to airports performance assessment considering undesirable outputs. Applied Mathematical Modelling 37(4), $1665-1676$.

[30] Pannu, H., Kumar, U.D., Farooquie, J.A. (2011). Efficiency and productivity analysis of Indian pharmaceutical industry using data envelopment analysis. International Journal of Operational Research 10(1), 121-136.

[31] Paradi JC, Asmild M, Simak PC (2004). Using DEA and Worst Practice DEA in Credit Risk Evaluation. Journal of Productivity Analysis 21, 153-165.

[32] Saaty TL (1986). Axiomatic foundation of the analytic hierarchy process. Management Science 32(7), 841-855.

[33] Seiford LM, Zhu J (1999). Infeasibility of super-efficiency data envelopment analysis models. INFOR 37(2), 174-187.

[34] Shabani A, Torabipour SMR, Saen RF, Khodakarami M (2015). Distinctive data envelopment analysis model for evaluating global environment performance. Applied Mathematical Modelling 39(15), 4385-4404.

[35] Shafiee, M, Lotfi, FH, Saleh, H (2015). Supply chain performance evaluation with data envelopment analysis and balanced scorecard approach. Applied Mathematical Modelling 38 (21-22), 5092-5112.

[36] Toloo, M. (2012). On finding the most BCC-efficient DMU: A new integrated MIP-DEA model. Applied Mathematical Modelling 36, 5515-5520.

[37] Toloo, M. (2013). The most efficient unit without explicit inputs: An extended MILP-DEA model. Measurement 46(9), 3628-3634.

[38] Kainuma Y, Tawara N (2006). A multiple attribute utility theory approach to lean and green supply chain management. International Journal of Production Economics 101(1), 99-108.

[39] Fernandez-Castro A, Smith P (1994) Towards a General Non-Parametric Model of Corporate Performance. Omega 22(3), 237-249.

[40] Takamura Y, Tone K (2003). A comparative site evaluation study for relocating Japanese government agencies out of Tokyo. Socio-Economic Planning Sciences 37, 85-102.

[41] Thanassoulis E (1999). Setting Achievements Targets for School Children. Education Economics 7(2), 101-119.

[42] Thompson RG, Singleton Jr FD, Thrall RM, Smith BA (1986). Comparative site evaluation for locating a high-energy physics lab in Texas. Interfaces 16, 35-49.

[43] Tone K (2002). A slacks-based measure of super-efficiency in Data Envelopment Analysis. European Journal of Operational Research 143, 32-41. 
[44] Tracy DL, Chen B (2005). A generalized model for weight restrictions in data envelopment analysis. Journal of the Operational Research Society 56, 390-396.

[45] Von Winterfeldt D, Edwards W (1986). Decisional Analysis and Behavioral Research. Cambridge University Press, New York.

[46] Wang YM, Luo Y (2006). DEA efficiency assessment using ideal and anti-ideal decision making units. Applied Mathematics and Computation 173, 902-915.

[47] Wu D (2006). A note on DEA efficiency assessment using ideal point: An improvement of Wang and Luo's model, Applied Mathematics and Computation 183, 819-830.

[48] Yamada Y, Matsui T, Sugiyama M (1994). An inefficiency measurement method for management systems, Journal of the Operations Research Society of Japan 37, 158-67.

[49] Yang GL, Shen WF, Zhang DQ, Liu WB (2014). Extended Utility and DEA Models without Explicit Input. Journal of the Operational Research Society 65, 1212-1220.

[50] Yao C (2005). Measuring super-efficiency in DEA in the presence of infeasibility. European Journal of Operational Research 161(2), 545-551.

[51] Zeleny M (1982). Multiple Criteria Decision Making, McGraw-Hill, New York. 
Table 1: Input/output indicators

\begin{tabular}{|c|c|c|c|}
\hline Indicators & Type & Units & Explanations \\
\hline $\begin{array}{l}\text { SCI Pub. I } \\
\text { Staff }\end{array}$ & $\begin{array}{l}\text { Ratio } \\
\text { indicator }\end{array}$ & $\begin{array}{l}\text { Number / Full } \\
\text { Time Equivalent } \\
\text { (FTE) }\end{array}$ & $\begin{array}{l}\text { The ratio of number of international papers indexed by } \\
\text { the Web of Science published by Thompson Reuters } \\
\text { divided by FTE of full-time research staff. }\end{array}$ \\
\hline $\begin{array}{l}\text { High Pub. / } \\
\text { Staff }\end{array}$ & $\begin{array}{l}\text { Ratio } \\
\text { indicator }\end{array}$ & Number/FTE & $\begin{array}{l}\text { The ratio of number of high-quality papers published in } \\
\text { top research journals (e.g., journals with top } 15 \% \\
\text { impact factors) divided by FTE of full-time research } \\
\text { staff. }\end{array}$ \\
\hline $\begin{array}{l}\text { Grad. Enroll. } \\
\text { / Staff }\end{array}$ & $\begin{array}{l}\text { Ratio } \\
\text { indicator }\end{array}$ & Number/FTE & $\begin{array}{l}\text { The ratio of number of graduate students' enrolment in } \\
2009 \text { divided by FTE of full-time research staff. }\end{array}$ \\
\hline $\begin{array}{l}\text { Exter. Fund / } \\
\text { Staff }\end{array}$ & $\begin{array}{l}\text { Ratio } \\
\text { indicator }\end{array}$ & $\begin{array}{l}\text { RMB in million } \\
\text { /FTE }\end{array}$ & $\begin{array}{l}\text { The ratio of amount of external research funding from } \\
\text { research contracts divided by FTE of full-time research } \\
\text { staff. }\end{array}$ \\
\hline Awards/ Staff & $\begin{array}{l}\text { Ratio } \\
\text { indicator }\end{array}$ & Score /FTE & $\begin{array}{l}\text { The ratio of awards score divided by FTE of full-time } \\
\text { research staff, where award score is defined as follows: } \\
\text { for the award indicator, the awards are divided into } \\
\text { different levels according to the importance and impact } \\
\text { of the awards. Each level is given different weighted } \\
\text { scores. The institutes' score of award indicator is } \\
\text { achieving by summing up the weighted scores of the } \\
\text { awards they obtained. }\end{array}$ \\
\hline
\end{tabular}


Table 2: Standardized indices

\begin{tabular}{|c|c|c|c|c|c|c|}
\hline Institutes & $\mathbf{y}_{\mathbf{1 j}}$ & $\mathbf{y}_{2 j}$ & $\mathbf{y}_{3 \mathbf{j}}$ & $\mathbf{y}_{4 j}$ & $\mathbf{y}_{\mathbf{5 j}}$ & $\mathbf{y}_{\mathbf{1 j}} * \mathbf{y}_{\mathbf{4}} \mathbf{j}$ \\
\hline $\mathrm{DMU}_{1}$ & 0.4596 & 0.2367 & 0.7899 & 0.1341 & 0.8598 & 0.0616 \\
\hline $\mathrm{DMU}_{2}$ & 0.5925 & 0.3916 & 0.7196 & 0.6226 & 0.3869 & 0.3689 \\
\hline $\mathrm{DMU}_{3}$ & 1.0000 & 1.0000 & 0.7797 & 0.1847 & 0.7895 & 0.1847 \\
\hline $\mathrm{DMU}_{4}$ & 0.2122 & 0.1616 & 0.3390 & 0.2096 & 0.5975 & 0.0445 \\
\hline $\mathrm{DMU}_{5}$ & 0.1970 & 0.0920 & 0.5207 & 0.4486 & 0.0000 & 0.0884 \\
\hline $\mathrm{DMU}_{6}$ & 0.5993 & 0.1878 & 1.0000 & 0.6774 & 0.3119 & 0.4060 \\
\hline $\mathrm{DMU}_{7}$ & 0.2149 & 0.1277 & 0.2419 & 0.3169 & 0.8993 & 0.0681 \\
\hline $\mathrm{DMU}_{8}$ & 0.1260 & 0.0603 & 0.3719 & 0.1202 & 0.0247 & 0.0151 \\
\hline $\mathrm{DMU}_{9}$ & 0.2381 & 0.2766 & 0.4481 & 0.6303 & 0.4344 & 0.1501 \\
\hline $\mathrm{DMU}_{10}$ & 0.5469 & 0.4247 & 0.7072 & 0.4854 & 1.0000 & 0.2655 \\
\hline $\mathrm{DMU}_{11}$ & 0.2279 & 0.1422 & 0.2252 & 0.7868 & 0.2377 & 0.1793 \\
\hline $\mathrm{DMU}_{12}$ & 0.1763 & 0.0955 & 0.5255 & 1.0000 & 0.2182 & 0.1763 \\
\hline $\mathrm{DMU}_{13}$ & 0.2567 & 0.2073 & 0.6844 & 0.3535 & 0.7700 & 0.0908 \\
\hline $\mathrm{DMU}_{14}$ & 0.2319 & 0.0582 & 0.3522 & 0.1184 & 0.6720 & 0.0275 \\
\hline $\mathrm{DMU}_{15}$ & 0.2953 & 0.3086 & 0.4829 & 0.3650 & 0.0000 & 0.1078 \\
\hline $\mathrm{DMU}_{16}$ & 0.0288 & 0.0042 & 0.4530 & 0.1310 & 0.0000 & 0.0038 \\
\hline
\end{tabular}


Table 3: The performance scores of 16 research institutes in 2009

\begin{tabular}{llcccc}
\hline MMU & $\left(q \theta_{\text {radial }}^{*}\right)$ & & Model 10 & \multicolumn{2}{c}{ Index 2 } \\
& Scores & Rank & Scores & Performance scores & Rank \\
\hline DMU $_{\mathbf{1}}$ & $\mathbf{1 . 0 0 0 0}$ & $\mathbf{1}$ & $\mathbf{0 . 8 8 2 9}$ & $\mathbf{1 . 0 0 0 0}+\boldsymbol{\varepsilon}^{*} \mathbf{0 . 1 1 7 1}$ & $\mathbf{6}$ \\
\hline $\mathbf{D M U}_{\mathbf{2}}$ & $\mathbf{1 . 0 0 0 0}$ & $\mathbf{1}$ & $\mathbf{0 . 4 5 2 7}$ & $\mathbf{1 . 0 0 0 0}+\boldsymbol{\varepsilon}^{*} \mathbf{0 . 5 4 7 3}$ & $\mathbf{3}$ \\
\hline $\mathbf{D M U}_{\mathbf{3}}$ & $\mathbf{1 . 0 0 0 0}$ & $\mathbf{1}$ & $\mathbf{0 . 6 4 3 5}$ & $\mathbf{1 . 0 0 0 0}+\boldsymbol{\varepsilon}^{*} \mathbf{0 . 3 5 6 5}$ & $\mathbf{4}$ \\
\hline $\mathrm{DMU}_{4}$ & 1.6736 & 13 & 0.9319 & $0.5975+\varepsilon^{*} 0.0681$ & 13 \\
\hline $\mathrm{DMU}_{5}$ & 1.6911 & 14 & 0.8700 & $0.5913+\varepsilon^{*} 0.1300$ & 14 \\
\hline $\mathbf{D M U}_{\mathbf{6}}$ & $\mathbf{1 . 0 0 0 0}$ & $\mathbf{1}$ & $\mathbf{0 . 3 5 5 6}$ & $\mathbf{1 . 0 0 0 0}+\boldsymbol{\varepsilon}^{*} \mathbf{0 . 6 4 4 4}$ & $\mathbf{1}$ \\
\hline $\mathrm{DMU}_{7}$ & 1.1120 & 7 & 1.0000 & $0.8993+\varepsilon^{*} 0.0000$ & 7 \\
\hline $\mathrm{DMU}_{8}$ & 2.6889 & 16 & 1.0000 & $0.3719+\varepsilon^{*} 0.0000$ & 16 \\
\hline $\mathrm{DMU}_{9}$ & 1.1715 & 10 & 0.6809 & $0.8536+\varepsilon^{*} 0.3191$ & 10 \\
\hline $\mathbf{D M U}_{\mathbf{1 0}}$ & $\mathbf{1 . 0 0 0 0}$ & $\mathbf{1}$ & $\mathbf{0 . 4 3 9 0}$ & $\mathbf{1 . 0 0 0 0}+\boldsymbol{\varepsilon}^{*} \mathbf{0 . 5 6 1 0}$ & $\mathbf{2}$ \\
\hline $\mathrm{DMU}_{11}$ & 1.1614 & 9 & 1.0000 & $0.8610+\varepsilon^{*} 0.0000$ & 9 \\
\hline $\mathbf{D M U}_{\mathbf{1 2}}$ & $\mathbf{1 . 0 0 0 0}$ & $\mathbf{1}$ & $\mathbf{0 . 6 7 2 4}$ & $\mathbf{1 . 0 0 0 0}+\boldsymbol{\varepsilon}^{*} \mathbf{0 . 3 2 7 6}$ & $\mathbf{5}$ \\
\hline $\mathrm{DMU}_{13}$ & 1.1265 & 8 & 0.5124 & $0.8877+\varepsilon^{*} 0.4876$ & 8 \\
\hline $\mathrm{DMU}_{14}$ & 1.4881 & 11 & 1.0000 & $0.6720+\varepsilon^{*} 0.0000$ & 11 \\
\hline $\mathrm{DMU}_{15}$ & 1.5823 & 12 & 0.9381 & $0.6320+\varepsilon^{*} 0.0619$ & 12 \\
\hline $\mathrm{DMU}_{16}$ & 2.2075 & 15 & 1.0000 & $0.4530+\varepsilon^{*} 0.0000$ & 15 \\
\hline
\end{tabular}


Appendix A

Table A-1: Assessment of playmakers

\begin{tabular}{|c|c|c|c|c|c|c|c|c|c|c|c|c|c|}
\hline Player & AFG & AFT & REB & AST & STE & ITURN & $\begin{array}{c}\mathrm{NF} \\
\mathrm{O}\end{array}$ & FOPP & model (7) & model (8) & $\begin{array}{c}\text { model } \\
(15)\end{array}$ & Index 1 & Ranking \\
\hline Bennett, Elmer & 5.68 & 3.4 & 2.94 & 6.06 & 1.94 & 0.36 & 2.24 & 6.33 & 1.0000 & 0.9284 & & $1+\varepsilon * 0.0716$ & 5 \\
\hline Victoriano, L. & 0.83 & 0.87 & 1.54 & 1.88 & 1.04 & 0.89 & 2.38 & 1.79 & 1.3373 & 1.0000 & & $0.7478+\varepsilon^{*} 0$ & 40 \\
\hline Herna'ndez, B. & 1.21 & 0.63 & 1.75 & 1.97 & 0.66 & 0.76 & 2.94 & 0.84 & 1.2008 & 1.0000 & & $0.8328+\varepsilon^{*} 0$ & 36 \\
\hline Sa'nchez, Pepe & 2.42 & 1.21 & 3.71 & 6.33 & 1.76 & 0.4 & 2.62 & 2.57 & 1.0000 & 1.0000 & 1.0923 & $1+\varepsilon *(-0.0923)$ & 9 \\
\hline Gomis, Joseph & 4.18 & 1.91 & 1.61 & 1.91 & 0.76 & 0.52 & 2.39 & 2.88 & 1.1943 & 1.0000 & & $0.8373+\varepsilon^{*} 0$ & 35 \\
\hline Lewis, Danny & 2.85 & 1.59 & 1.62 & 1.85 & 1.15 & 0.57 & 2.71 & 2.85 & 1.1511 & 1.0000 & & $0.8687+\varepsilon^{*} 0$ & 32 \\
\hline Rodri'guez, Javi & 2.42 & 2.89 & 3.06 & 4.65 & 1.59 & 0.33 & 1.88 & 5.12 & 1.0413 & 1.0000 & & $0.9603+\varepsilon^{*} 0$ & 19 \\
\hline Larraga'n, Borja & 1.36 & 0.4 & 0.34 & 1.1 & 0.34 & 1.53 & 3.55 & 0.9 & 1.0851 & 1.0000 & & $0.9216+\varepsilon^{*} 0$ & 27 \\
\hline Comas, Jaume & 3.16 & 1.66 & 1.88 & 2.47 & 1.76 & 0.55 & 2.03 & 3.03 & 1.1639 & 1.0000 & & $0.8592+\varepsilon * 0$ & 33 \\
\hline Rodilla, Nacho & 2.35 & 1.47 & 1.55 & 1.73 & 0.88 & 0.94 & 3.39 & 2.79 & 1.0147 & 0.8313 & & $0.9855+\varepsilon * 0.1687$ & 15 \\
\hline Galilea, J.L. & 3.62 & 0.58 & 1.41 & 2.91 & 0.81 & 0.57 & 2.66 & 1.81 & 1.1249 & 1.0000 & & $0.889+\varepsilon^{*} 0$ & 30 \\
\hline 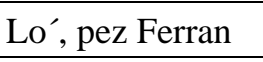 & 2.12 & 0.5 & 1.53 & 2.12 & 0.85 & 0.63 & 3.47 & 1.68 & 1.0226 & 1.0000 & & $0.9779+\varepsilon^{*} 0$ & 16 \\
\hline Santangelo, M. & 5.44 & 1.06 & 2.18 & 2.71 & 1 & 0.6 & 2.71 & 2.47 & 1.0000 & 0.9188 & & $1+\varepsilon * 0.0812$ & 4 \\
\hline Cherry, Carlos & 1.61 & 1.13 & 0.97 & 1.24 & 0.85 & 0.87 & 3.41 & 1.88 & 1.0623 & 1.0000 & & $0.9414+\varepsilon * 0$ & 22 \\
\hline Rodr1'guez, N. & 1.61 & 1.07 & 2.15 & 2.24 & 1.38 & 0.87 & 3.53 & 1.97 & 1.0000 & 0.8555 & & $1+\varepsilon^{*} 0.1445$ & 2 \\
\hline Mart1'nez, G. & 2.25 & 0.84 & 2.1 & 3.8 & 0.67 & 0.64 & 2.93 & 1.83 & 1.0814 & 0.9985 & & $0.9247+\varepsilon^{*} 0.0015$ & 25 \\
\hline Reyne's, P. & 3.02 & 0.69 & 1.76 & 2.38 & 0.65 & 0.6 & 3.29 & 2.03 & 1.0140 & 1.0000 & & $0.9862+\varepsilon^{*} 0$ & 14 \\
\hline Johnson, Sydney & 2.37 & 0.91 & 2.68 & 2.71 & 1.21 & 0.56 & 2.76 & 2.88 & 1.0673 & 1.0000 & & $0.9369+\varepsilon^{*} 0$ & 24 \\
\hline Jofresa, Rafa & 2.13 & 1.02 & 1.17 & 1.13 & 0.42 & 0.73 & 3.21 & 1.29 & 1.1321 & 1.0000 & & $0.8833+\varepsilon^{*} 0$ & 31 \\
\hline Montecchia, A. & 4.96 & 1.01 & 2.28 & 2.38 & 1.38 & 0.71 & 1.94 & 1.69 & 1.0823 & 1.0000 & & $0.924+\varepsilon^{*} 0$ & 26 \\
\hline
\end{tabular}




\begin{tabular}{|c|c|c|c|c|c|c|c|c|c|c|c|c|c|}
\hline Llompart, Pedro & 0.89 & 0.31 & 0.35 & 0.65 & 0.12 & 2.43 & 3.82 & 0.88 & 1.0274 & 1.0000 & & $0.9733+\varepsilon * 0$ & 17 \\
\hline Popovic, Marko & 1.86 & 1.63 & 0.82 & 1.36 & 0.55 & 0.88 & 3.32 & 2.64 & 1.0355 & 1.0000 & & $0.9657+\varepsilon^{*} 0$ & 18 \\
\hline Corrales, Iva'n & 3.08 & 1.41 & 1.5 & 4.38 & 0.97 & 0.35 & 2 & 2.38 & 1.2889 & 1.0000 & & $0.7759+\varepsilon^{*} 0$ & 39 \\
\hline Gil, David & 0.72 & 0.82 & 0.97 & 1.58 & 0.21 & 0.92 & 4.06 & 1.3 & 1.0000 & 1.0000 & 1.6135 & $1+\varepsilon^{*}(-0.6135)$ & 12 \\
\hline Prigioni, Pablo & 2.37 & 0.89 & 1.94 & 3.52 & 2.13 & 0.86 & 2.52 & 1.42 & 1.0000 & 0.9069 & & $1+\varepsilon^{*} 0.0931$ & 3 \\
\hline Caldero’n, J.M. & 3.57 & 1.3 & 2.82 & 2.18 & 1.3 & 1.03 & 3.09 & 1.94 & 1.0000 & 0.8103 & & $1+\varepsilon * 0.1897$ & 1 \\
\hline Brewer, Corey & 3.85 & 1.32 & 1.94 & 1.35 & 0.76 & 0.54 & 2.65 & 2.88 & 1.1249 & 1.0000 & & $0.889+\varepsilon^{*} 0$ & 29 \\
\hline Azofra, Nacho & 3.32 & 0.9 & 1.65 & 2.88 & 0.94 & 0.79 & 1.71 & 1.44 & 1.3660 & 1.0000 & & $0.7321+\varepsilon * 0$ & 41 \\
\hline Miso, Andre's & 2.09 & 0.54 & 1 & 0.63 & 0.46 & 1.71 & 3.79 & 1.38 & 1.0000 & 1.0000 & 1.2007 & $1+\varepsilon^{*}(-0.2007)$ & 11 \\
\hline Marco, Carles & 4.89 & 1.64 & 2.03 & 4.15 & 1.06 & 0.4 & 2.41 & 2.38 & 1.0637 & 0.9683 & & $0.9401+\varepsilon * 0.0317$ & 23 \\
\hline Dumas, Stephane & 1.91 & 0.85 & 1.41 & 2.06 & 0.76 & 0.71 & 3.29 & 1.47 & 1.0861 & 0.9768 & & $0.9207+\varepsilon * 0.0232$ & 28 \\
\hline Guzma'n, J.M. & 1.29 & 0.49 & 1.47 & 1.74 & 0.53 & 0.95 & 3.11 & 1.53 & 1.1736 & 1.0000 & & $0.8521+\varepsilon * 0$ & 34 \\
\hline Oliver, Albert & 3.08 & 3.07 & 3.44 & 3.09 & 1.21 & 0.56 & 2 & 4.44 & 1.0000 & 0.9656 & & $1+\varepsilon * 0.0344$ & 7 \\
\hline Cistero', Maiol & 0.49 & 0.42 & 0.7 & 1.06 & 0.33 & 1.83 & 3.06 & 0.67 & 1.2387 & 1.0000 & & $0.8073+\varepsilon * 0$ & 38 \\
\hline Martı'nez, Rafa & 1.09 & 0.56 & 0.72 & 0.63 & 0.47 & 2.67 & 3.91 & 1.31 & 1.0000 & 1.0000 & 1.0257 & $1+\varepsilon^{*}(-0.0257)$ & 8 \\
\hline Bullock, Louis & 7.63 & 3.68 & 2.76 & 1.94 & 0.91 & 0.58 & 2.21 & 4.24 & 1.0000 & 0.9643 & & $1+\varepsilon^{*} 0.0357$ & 6 \\
\hline Cabezas, Carlos & 2.6 & 1.32 & 1.79 & 1.29 & 0.68 & 0.87 & 3.24 & 1.76 & 1.0610 & 0.9222 & & $0.9425+\varepsilon * 0.0778$ & 21 \\
\hline Turner, Andre & 4.97 & 2.31 & 2.41 & 4.53 & 1.74 & 0.37 & 2.47 & 3.62 & 1.0105 & 0.9450 & & $0.9896+\varepsilon * 0.055$ & 13 \\
\hline Monta'ñ, ez Roma'n & 5.28 & 2.52 & 1.71 & 1.68 & 1.18 & 0.44 & 1.56 & 4.26 & 1.2128 & 1.0000 & & $0.8245+\varepsilon * 0$ & 37 \\
\hline San, Emeterio & 1.88 & 0.97 & 2.76 & 1.29 & 0.85 & 0.92 & 2.88 & 2.03 & 1.0492 & 1.0000 & & $0.9531+\varepsilon * 0$ & 20 \\
\hline Mc, Guthrie C. & 1.79 & 0.64 & 0.52 & 1.43 & 0.52 & 1.21 & 3.78 & 0.74 & 1.0000 & 1.0000 & 1.1763 & $1+\varepsilon^{*}(-0.1763)$ & 10 \\
\hline
\end{tabular}


Table A-2: Assessment of centers

\begin{tabular}{|c|c|c|c|c|c|c|c|c|c|c|c|c|c|}
\hline Player & AFG & AFT & REB & AST & STE & ITURN & NFO & FOPP & model (7) & model (8) & model (15) & Index 1 & Ranking \\
\hline Kambala, K. & 9.23 & 2.55 & 6.06 & 0.31 & 0.66 & 0.45 & 1.44 & 4.63 & 1.0000 & 1.0000 & 1.2749 & $1+\varepsilon^{*}(-0.2749)$ & 11 \\
\hline Bueno, Antonio & 3.29 & 0.76 & 2.57 & 0.18 & 0.32 & 0.88 & 2.68 & 1.39 & 1.1958 & 1.0000 & & $0.8363+\varepsilon * 0$ & 33 \\
\hline De, Miguel I. & 3.09 & 1.11 & 4.12 & 0.94 & 1.35 & 0.81 & 1.26 & 3.06 & 1.0276 & 1.0000 & & $0.9731+\varepsilon * 0$ & 18 \\
\hline Junyent, Oriol & 4.52 & 1.57 & 4.8 & 0.8 & 0.53 & 0.67 & 1.87 & 2.43 & 1.2977 & 1.0000 & & $0.7706+\varepsilon * 0$ & 41 \\
\hline Garce's, Rube'n & 5.26 & 0.96 & 9.81 & 0.53 & 0.91 & 0.46 & 1.72 & 2.84 & 1.0000 & 1.0000 & 1.1420 & $1+\varepsilon^{*}(-0.1420)$ & 9 \\
\hline Gonza'lez, R. & 2.64 & 1.06 & 2.14 & 0.21 & 0.93 & 1.56 & 2.68 & 1.64 & 1.0580 & 0.9967 & & $0.9452+\varepsilon * 0.0033$ & 20 \\
\hline Ferna'ndez, P. & 1.31 & 0.31 & 2.23 & 0.13 & 0.58 & 1.19 & 2.55 & 0.84 & 1.2323 & 1.0000 & & $0.8115+\varepsilon^{*} 0$ & 36 \\
\hline Guardia, Salva & 4.58 & 1.9 & 4.74 & 0.53 & 0.56 & 0.67 & 1.76 & 2.97 & 1.2053 & 1.0000 & & $0.8297+\varepsilon * 0$ & 34 \\
\hline Jackson, Robert & 5.6 & 1.08 & 5.62 & 0.15 & 0.73 & 0.79 & 1.69 & 2.46 & 1.2473 & 1.0000 & & $0.8017+\varepsilon * 0$ & 39 \\
\hline Garcı'a, Dani & 1.6 & 0.11 & 1.82 & 0.5 & 0.12 & 3.78 & 3.32 & 0.32 & 1.0000 & 1.0000 & 2.5129 & $1+\varepsilon^{*}(-1.5129)$ & 13 \\
\hline Bramlett, A.J. & 5.73 & 0.65 & 8.06 & 1.44 & 0.88 & 0.47 & 1.21 & 2.56 & 1.1083 & 1.0000 & & $0.9023+\varepsilon * 0$ & 27 \\
\hline Alston, Derrick & 5.56 & 1.45 & 6.73 & 1.24 & 1.18 & 0.72 & 2.03 & 3.61 & 1.0481 & 0.8075 & & $0.9541+\varepsilon * 0.1925$ & 19 \\
\hline Scott, Brent & 8.82 & 2.43 & 9.15 & 1.91 & 0.71 & 0.3 & 1.47 & 5.65 & 1.0000 & 1.0000 & 1.2428 & $1+\varepsilon *(-0.2428)$ & 10 \\
\hline Reynolds-Dean, & 5.9 & 2.11 & 6.53 & 1.26 & 1.41 & 0.52 & 2.35 & 3 & 1.0000 & 0.9458 & & $1+\varepsilon^{*} 0.0542$ & 3 \\
\hline Horton, Steve & 0.56 & 0.19 & 1.48 & 0.04 & 0.48 & 4.5 & 3.41 & 0.78 & 1.0000 & 1.0000 & 3 & $1+\varepsilon *(-2.0000)$ & 14 \\
\hline Jones, Alvin & 2.43 & 0.91 & 5 & 0.33 & 0.79 & 0.77 & 2.58 & 2.46 & 1.0643 & 1.0000 & & $0.9396+\varepsilon^{*} 0$ & 22 \\
\hline Mikhailov, M. & 1.31 & 0.08 & 3.6 & 0.6 & 0.57 & 1.58 & 3.2 & 1.2 & 1.0183 & 0.9507 & & $0.982+\varepsilon * 0.0493$ & 17 \\
\hline Femerling, $\mathrm{P}$. & 3.59 & 1.42 & 5.27 & 0.82 & 0.82 & 0.67 & 2.36 & 2.97 & 1.0729 & 0.9840 & & $0.9321+\varepsilon * 0.016$ & 23 \\
\hline Duen , as Roberto & 3.54 & 0.67 & 5.19 & 0.5 & 0.34 & 0.63 & 2.94 & 1.5 & 1.0005 & 1.0000 & & $0.9995+\varepsilon * 0$ & 15 \\
\hline Varejao, A. & 3.88 & 0.83 & 4.41 & 1.04 & 1.26 & 0.79 & 2 & 2.59 & 1.1349 & 0.9456 & & $0.8811+\varepsilon * 0.0544$ & 29 \\
\hline Va'zquez, Fran & 3.78 & 0.88 & 4.18 & 0.21 & 0.27 & 1.32 & 2.82 & 1.67 & 1.0953 & 1.0000 & & $0.913+\varepsilon^{*} 0$ & 26 \\
\hline Burke, Pat & 5.93 & 0.87 & 5.35 & 0.25 & 0.65 & 0.65 & 2.7 & 1.75 & 1.0000 & 1.0000 & 1.1352 & $1+\varepsilon^{*}(-0.1352)$ & 8 \\
\hline Thomas, John & 5.25 & 1.47 & 5.13 & 0.52 & 0.84 & 0.52 & 1.48 & 2.55 & 1.3318 & 1.0000 & & $0.7509+\varepsilon * 0$ & 42 \\
\hline
\end{tabular}




\begin{tabular}{|c|c|c|c|c|c|c|c|c|c|c|c|c|c|}
\hline Struelens, Eric & 3.81 & 0.64 & 5.22 & 0.75 & 0.69 & 0.71 & 2.22 & 1.28 & 1.1911 & 1.0000 & & $0.8396+\varepsilon * 0$ & 32 \\
\hline Rogers, Paul & 2.27 & 0.26 & 4.33 & 0.29 & 0.54 & 1.2 & 2.83 & 1.58 & 1.0781 & 1.0000 & & $0.9276+\varepsilon * 0$ & 24 \\
\hline Oberto, F. & 7.05 & 0.5 & 5.35 & 1.82 & 0.94 & 0.5 & 1.65 & 2.85 & 1.0620 & 1.0000 & & $0.9416+\varepsilon * 0$ & 21 \\
\hline Tomasevic, D. & 4.55 & 0.78 & 7.5 & 3.15 & 1.56 & 0.52 & 2.15 & 3.18 & 1.0000 & 1.0000 & 1.0200 & $1+\varepsilon^{*}(-0.0200)$ & 6 \\
\hline Garc1’a, Asier & 2.21 & 0.57 & 1.67 & 0.52 & 0.19 & 1.59 & 3.52 & 0.63 & 1.0000 & 1.0000 & 1.3553 & $1+\varepsilon^{*}(-0.3553)$ & 12 \\
\hline Toledo, S. & 3.08 & 0.4 & 2.91 & 0.5 & 0.38 & 1.52 & 3.5 & 1.09 & 1.0000 & 0.8704 & & $1+\varepsilon * 0.1296$ & 1 \\
\hline Guille'n, R. & 2.41 & 1 & 2.48 & 0.28 & 0.24 & 2.64 & 3.59 & 1 & 1.0000 & 0.9596 & & $1+\varepsilon * 0.0404$ & 4 \\
\hline Savane, Sitapha & 6.45 & 1.54 & 5.67 & 0.8 & 0.73 & 0.64 & 1.8 & 3.5 & 1.1523 & 0.9087 & & $0.8678+\varepsilon * 0.0913$ & 31 \\
\hline David, Kornel & 7.25 & 2.61 & 5.12 & 1.53 & 0.97 & 0.62 & 1.5 & 2.85 & 1.0000 & 0.9603 & & $1+\varepsilon * 0.0397$ & 5 \\
\hline Betts, Andrew & 3.98 & 0.87 & 3.45 & 0.8 & 0.55 & 0.8 & 1.8 & 2.35 & 1.4086 & 1.0000 & & $0.7099+\varepsilon * 0$ & 43 \\
\hline Jelic, Dusan & 1.52 & 0.5 & 2.53 & 0.12 & 0.29 & 2.13 & 2.65 & 1.24 & 1.2442 & 1.0000 & & $0.8037+\varepsilon * 0$ & 38 \\
\hline Reyes, Felipe & 8.25 & 1.86 & 8.24 & 1.59 & 1.09 & 0.34 & 1.76 & 5.12 & 1.0000 & 1.0000 & 1.0269 & $1+\varepsilon^{*}(-0.0269)$ & 7 \\
\hline Tabak, Zan & 7.64 & 0.87 & 7.09 & 1.18 & 0.44 & 0.44 & 2 & 2.82 & 1.0032 & 1.0000 & & $0.9968+\varepsilon * 0$ & 16 \\
\hline Alzamora, Alf. & 3.05 & 1.68 & 3.12 & 0.74 & 0.76 & 1.03 & 2.18 & 2.94 & 1.1257 & 0.9228 & & $0.8883+\varepsilon * 0.0772$ & 28 \\
\hline Brown, John & 6.83 & 1.02 & 6.06 & 0.79 & 0.65 & 0.47 & 1.94 & 2.38 & 1.0922 & 1.0000 & & $0.9156+\varepsilon * 0$ & 25 \\
\hline Llorens, Jordi & 1.32 & 0.44 & 2.73 & 0.24 & 0.33 & 1.03 & 2.06 & 1.18 & 1.5368 & 1.0000 & & $0.6507+\varepsilon * 0$ & 44 \\
\hline Kornegay, Chuck & 3.81 & 0.74 & 5.83 & 0.5 & 0.8 & 0.63 & 1.8 & 2.2 & 1.2810 & 1.0000 & & $0.7806+\varepsilon * 0$ & 40 \\
\hline Gabriel, Germa'n & 3.38 & 0.79 & 3.06 & 0.32 & 0.59 & 0.81 & 2.59 & 1.97 & 1.1419 & 1.0000 & & $0.8757+\varepsilon * 0$ & 30 \\
\hline Weis, Frederic & 0.82 & 0.06 & 2.7 & 0.2 & 0.35 & 1.54 & 2.75 & 0.95 & 1.2279 & 1.0000 & & $0.8144+\varepsilon * 0$ & 35 \\
\hline Thompson, Kevin & 8.1 & 2.52 & 9.53 & 1.09 & 0.94 & 0.46 & 1.88 & 4.68 & 1.0000 & 0.8874 & & $1+\varepsilon * 0.1126$ & 2 \\
\hline Ferna'ndez, G. & 4.54 & 0.73 & 2.56 & 0.26 & 0.41 & 0.94 & 2.18 & 1.35 & 1.2362 & 1.0000 & & $0.8089+\varepsilon * 0$ & 37 \\
\hline
\end{tabular}

